\title{
Long Term Load Forecasting of Jimma Town for Sustainable Energy Supply
}

\author{
Emiyamrew Minaye ${ }^{1}$, Melaku Matewose ${ }^{2}$ \\ ${ }^{1}$ Jimma University, Jimma Institute of Technology, Department of Biomedical Engineering, Jimma, Ethiopia \\ ${ }^{2}$ Jimma University, Jimma Institute of Technology, School of Electrical and Computer Engineering, Jimma, Ethiopia
}

\begin{abstract}
Now a day, due to economic development of the country the electrical energy demand of Ethiopia increases by $30 \%$ yearly. But in order to satisfy customers' power demand the planning and expansion of power must be done using a proper load forecasting methods. Due to this demand forecasting is a vital and integral process for planning periodical operations and facility expansion in the electricity sector. Even though demand forecasting is a central process its' pattern is almost very complex due to the deregulation of energy markets. Therefore, finding an appropriate forecasting model that will generalize the demand patter for a specific electricity network may not be an easy task. This paper presents a realistic methodology that can be used as a guide to construct Jimma town Electric Power Load Forecasting models. Trending methodology statistical analyses are involved to study the load features and forecasting precision, such as linear regression, compound growth model and quadratic regression. Real monthly and yearly load data from Jimma distribution system substation is used as a case study. By using the best optimal value of the rank correlation coefficient and mean absolute percentage error, the compound growth model is used in the coming five years load forecasting. By forecasting of Jimma town load demand will result in proper utilization of energy and for planning of any electricity related projects it will use as a baseline to be applied cost wise. The main objective of this study is to assess the future energy demand of customers so that supplying of power and using that without shortage will be optimized.
\end{abstract}

Keywords: Energy, Forecasting, Long term, Trend analysis, Customers

\section{Introduction}

Jimma is one of the zones of Oromo region which found in south west part of the Capital city of Ethiopia. Before 1989 the town got electricity from diesel generators. The town's substation was started its function in 1989 with a 6.3 MVA transformer rating. At that time the peak load consumptions was 1.5 MW. In 2005 the substation was upgraded to 20 MVA which is working up to now. Now a day the town utilizes a maximum of around $15 \mathrm{MW}$ power..

Electric power is the vital part in the development of any country. In order to supply power to the customers based on their demand the generation system, transmission system and distribution systems must be designed by considering load demand forecasting.

Among these, the distribution system is the essential link to the customers. When electric power distribution systems are designed and operated it shall to be considered long term and short term demand forecasting.

Electric Power Load Forecasting (EPLF) is a vital process in the planning of the electricity industry and the operation of electric power systems. Accurate forecasts lead to substantial savings in operating and maintenance costs, increased reliability of power supply and delivery system, and correct decisions for future development

Long-term demand forecasts span from years up to decades. They have an important role in the context of generation, transmission and distribution network planning in a power system. The main objective of power system planning is to determine an economic expansion of the equipment and facilities to meet the customers' future electricity demand with an acceptable level of reliability and power quality [3].
Accurate long-term demand forecasting plays an essential role in electric power system planning. It corresponds to load demand forecasting with direct times enough to plan for long-term maintenance, construction scheduling for developing new generation facilities, purchasing of generating units, developing transmission and distribution systems. The accuracy of the long-term load forecast has a significant effect on developing future generation and distribution planning. An expensive overestimation of load demand will result in substantial investment, for the construction of excess power facilities, while underestimation will result in customer discontentment. Unfortunately, it is difficult to forecast load demand accurately over a planning period of several years. This fact is due to the uncertain nature of the forecasting process.

There are a large number of influential that characterize and directly or indirectly affect the underlying forecasting process [4]. However, neither the accurate amount of needed power nor the preparation for such amounts of power is as easy as it looks.

The reasons are:

1) Long-term load forecasting is always inaccurate as the years increase

2) Peak demand is very much dependant on weather condition

3) Unavailability of weather and economical data

4) It is very difficult to store electric power with the present technology,

5) It takes several years and requires a great amount of investment to construct new power generation stations and transmission facilities [4]. Therefore, any long-term load demand forecasting, by nature, is inaccurate. 


\section{International Journal of Science and Research (IJSR) ISSN (Online): 2319-7064 \\ Index Copernicus Value (2013): 6.14 | Impact Factor (2014): 5.611}

\section{Review of Literature}

Due to many factors electric power systems are tremendously complex. It consists of uncounted numbers of facilities and structures, systems and subsystems, components and equipment, and the complex physical, Administrative and operational interactions. Physical interactions are interaction between parts of the facilities, systems, and components, whereas operational interactions are the interactions where the equipment electrically, magnetically, or mechanically interacts with other equipment. Administrative interactions are the interactions where the facilities and structures, systems and subsystems, components and equipment are subjected to management and administrative procedures, which include a wide set of documents [1]. So if the electric power system has those characteristics and since the energy once generated cannot be stored efficiently or effectively in large quantities, then the complexity unpredicted system behavior at one point of the system can have a major impact at large if planning is not done properly.

Considering the benefits that energy forecasting may bring to the security, economics and resource management fields, the scientific community is now beginning to take some interest in this area. The control of the performance prediction represents the premise of a good global performance. As load forecasting is highly related to the quality of system planning, attention has been paid to the impact of load forecasting on system design and economics [5].

Load forecasting is usually tied to reliability analysis and distribution transformer load management. Optimization software and techniques are applied to load forecasting as well as planning [10].

There is an array of methods that are available today for forecasting demand in the short term, medium term and long term. Some of these methods are simplistic; others are more sophisticated and require detailed and very accurate input data and information $[5,11]$

An appropriate method is chosen based on the nature of the data available and the desired nature and level of detail of the forecasts. Due to a lack of accurate and reliable input data, sometimes forecasters must employ more general approaches and consider various cases or scenarios in order to evaluate the sensitivity of results [18].

Even though there are various methods, algorithms, computer codes/programs in use for load forecasting, all fall into two categories namely parametric and artificial intelligence methods. Parametric load forecasting methods are based on statistical techniques and historical data of loads and factors affecting on loads. The parametric load forecasting method has three types: trending method, end use method and econometric approach method [14, 18].

Trending methods look for some function to fit the past load growth patterns and estimate the future load based on the function. The trending method uses a single to multivariate regression to fit a polynomial function to load history data.
The underlying notion of this analysis is that time is the factor determining the value of the variable under study, or, the pattern of the variable in the past will continue in the future. Therefore, it does not offer any scope to internalize the changes in factors such as the effects of government policy (pricing or other) underlying institutional structure, regulatory regimes, demographic trends, aggregate and per capita growth in incomes and technological developments [19]. The advantages of the trending method include ease of use, simplicity, and a short-range response to recent trends of load growth patterns. However, it often fails to have a useful estimate of the long-range load.

The end-use approach makes load forecasts based on the statistical information by considering the impact of energy usage patterns of various devices and systems. It focuses on various uses of the residential, commercial, agriculture and industrial sectors of the economy based on the principle that electricity demand is de-rived from customer's demand for light, heating, cooling, etc. This model use extensive information on end users, for instance, customer size and size of houses. The approach demands a high level of detail on each of the end-users. One criticism raised against the method is that it may lead to a mechanical forecasting of demands, without adequate regard for behavioral responses of consumers. It also does not give variations in the consumption patterns due to demographic, socioeconomic, or cultural factors [16].

This approach combines economic theory with statistical methods to produce a system of equations for forecasting energy demand. The demand for electricity is expressed as a function of various economic factors such as population, income per capita, price of electric power, prices of alternative fuels (that could be used as substitutes) and capture technology effect in the case of industries etc. The econometric methods require a consistent set of information over a reasonably long duration. This requirement forms a prerequisite for establishing both short-term and long-term relationships between the variables involved. The price effect will have an important role to play in the years to come. In such a case, one may have to broaden the set of explanatory variables apart from relying on more rigorous econometric techniques to get around the problem [18].

Systems approaches, including the use of extensions of the aforementioned methods can provide an organized framework for resources management and for estimating the important geographical, ecological, social and economic impacts and trends over relevant scales of space and time. The load is multi-dimensional variable so the methods used to forecast includes deep mathematics and modeling. Now a day, fuzzy logic, artificial intelligence and neural network are added the last generation methods for load forecasting.

\section{Materials and Methods}

For this study the load history of Jimma town in the years from $2009 / 10$ to $2013 / 14$ is used. The five years actual monthly peak load is collected from the south western transmission substation, maintenance and operation office and the years are based on Ethiopian fiscal year. 


\section{International Journal of Science and Research (IJSR) \\ ISSN (Online): 2319-7064}

Index Copernicus Value (2013): 6.14 | Impact Factor (2014): 5.611

Trending load forecasting is used for doing this research. The reasons were due to lack of necessary data that will use as input for other types of parametric load forecasting. This methodology predicts future power demand by assuming that the factors that influenced demand in the past will continue to do so in the same way in the future. The most common functions are linear trend regression, compound growth trend regression and quadratic trend regression $[6,7$, and 8$]$.

The Linear Model Approach: This simple model is used based on the linear relationship between the dependent variable $y$ which is the peak load of the year and independent variable $\mathrm{x}$ which is the year as shown in Equation (1). This is the equation of a straight line which intercepts y axes at $\alpha$ with a slope of $\beta$ [17]. In order to get the value of $\alpha$ and $\beta$, equations (2) and (3) used which are derived from the equation (1). The number of years is represented by $n$ in all the trending method used here.

$$
\begin{gathered}
y=\alpha+\beta x \\
\sum_{i=0}^{n} y_{i}=\alpha \mathrm{n}+\beta \sum_{i=0}^{n} x_{i} \\
\sum_{i=0}^{n} x_{i} y_{i}=\alpha \sum_{i=0}^{n} x_{i}+\beta \sum_{i=0}^{n} x_{i}{ }^{2}
\end{gathered}
$$

The Compound-Growth Model: - This is one of the trending load forecasting methods and it is expressed as equation (4)

$$
y=\operatorname{antilog}(r+s x)
$$

Where the constants $r$ and $s$ can be found by solving equation (5) and (6) simultaneously

$$
\begin{gathered}
\sum_{i=0}^{n} \log y_{i}=\mathrm{nr}+\mathrm{s} \sum_{i=0}^{n} x_{i} \\
\sum_{i=0}^{n} x_{i} \log y_{i}=\mathrm{r} \sum_{i=0}^{n} x_{i}+s \sum_{i=0}^{n} x_{i}^{2}
\end{gathered}
$$

The quadratic regression model: - This relates peak load (y) and the years ( $\mathrm{x}$ ) in the form given in equation (7)

$$
y=a_{0}+a_{1} x+a_{2} x^{2}
$$

While the constants $a_{0}, a_{1}$ and $a_{2}$ can be solved from the equations $(8,9$ and 10$)$;

$$
\begin{gathered}
\sum_{i=0}^{n} y_{i}=\mathrm{a}_{0} \mathrm{n}+\mathrm{a}_{1} \sum_{i=0}^{n} x_{i}+\mathrm{a}_{2} \sum_{i=0}^{n} x_{i}{ }^{2} \\
\sum_{i=0}^{n} x_{i} y_{i}=\mathrm{a}_{0} \sum_{i=0}^{n} x_{i}+\mathrm{a}_{1} \sum_{i=0}^{n} x_{i}{ }^{2}+\mathrm{a}_{2} \sum_{i=0}^{n} x_{i}{ }^{3}
\end{gathered}
$$$$
\sum_{i=0}^{n} x_{i}^{2} y_{i}=\mathrm{a}_{0} \sum_{i=0}^{n} x_{i}{ }^{2}+\mathrm{a}_{1} \sum_{i=0}^{n} x_{i}{ }^{3}+\mathrm{a}_{2} \sum_{i=0}^{n} x_{i}{ }^{4}
$$

Table 1: The compression of actual peak load and forecasted

\begin{tabular}{|c|c|c|c|c|}
\hline $\begin{array}{c}\text { Year } \\
(\mathrm{X})\end{array}$ & $\begin{array}{c}\text { Actual } \\
\text { peak load } \\
(\mathrm{MW})\end{array}$ & $\begin{array}{c}\text { Linear } \\
\text { trend } \\
\text { Forecasted } \\
\text { peak load } \\
(\mathrm{MW})\end{array}$ & $\begin{array}{c}\text { Compound } \\
\text { growth } \\
\text { Forecasted } \\
\text { peak load } \\
(\mathrm{MW})\end{array}$ & $\begin{array}{c}\text { Quadratic } \\
\text { regression model } \\
\text { Forecasted peak } \\
\text { load (MW) }\end{array}$ \\
\hline $2009 / 10$ & 7.6 & 7.5 & 7.66 & 7.74 \\
\hline $2010 / 11$ & 8.9 & 8.75 & 8.69 & 8.63 \\
\hline $2011 / 12$ & 9.8 & 10 & 9.85 & 9.76 \\
\hline $2012 / 13$ & 10.8 & 11.25 & 11.17 & 11.13 \\
\hline $2013 / 14$ & 12.9 & 12.5 & 12.66 & 12.74 \\
\hline
\end{tabular}

Based on the above mentioned trending load forecasting methods; in order to select the best one the rank of the correlation coefficient $r_{x y}$ and Mean absolute percentage error (MAPE) are used. Rank correlation coefficient $r_{x y}$ is a statistical tool that helps to measure and analyze the degree of relationship between the two variables $\mathrm{x}$ and $\mathrm{y}$. It tells how truthful the model can be in its forecast. Its optimal value is unity.

$$
r_{x y}=\frac{\sum_{i=0}^{n} x_{i} y_{i}-n \bar{x} \bar{y}}{n s_{x} s_{y}}
$$

Where $\bar{x}$ and $\bar{y}$ are the mean values of $\mathrm{x}$ and $\mathrm{y}$ and $s_{x}$ and $s_{y}$ are the standard deviation of $\mathrm{x}$ and $\mathrm{y}$ respectively.
Mean absolute percentage error (MAPE) is a measure of accuracy in a fitted time series value in statistical trending. It usually expresses accuracy as a percentage and is expressed as equation (12)

$$
M A P E=M=\frac{1}{n} \sum_{t=1}^{n}\left|\frac{A_{t}-F_{t}}{A_{t}}\right|
$$

Where At is the actual value and Ft is the forecast value. The least value of $\mathrm{M}$ is optimal unlike highest value of rank $r$ [15].

\section{Results and Tables}

In order to forecast Jimma town distribution system; linear trend, compound growth and quadratic regression methods are used. Using these methods the best rank correlation coefficient $\left(r_{x y}\right)$ and Mean absolute percentage error (MAPE) was selected.

From table 1 the starting year 2009/10 acts as 1 value of X and the last year 2013/14 will be the $\mathrm{X}$ value of 5 .

Based on this when the linear trend method is applied

$$
\begin{aligned}
& 50=5 \alpha+15 \beta \\
& 162.5=15 \alpha+55 \beta
\end{aligned}
$$

Solving the two equations simultaneously the value of $\alpha=6.25$ and $b=1.25$ so that the equation will be

$$
y=6.25+1.25 * x
$$

In case of Compound-Growth Model when the values of $x$ and $y$ are substituted in equation (5) and (6)

$4.965=5 r+15 s$

$15.44=15 r+55 s$

Solving the two equations simultaneous will give $r=0.83$ and $\mathrm{s}=0.0545$ so that equation 4 will be written as

$$
\mathrm{y}=\operatorname{antilog}(0.83+0.0545 * \mathrm{x})
$$

In case of the quadratic regression model, by substituting the values of $x$ and $y$ in equation (8) to (10) it will be

$$
\begin{gathered}
50=5 \mathrm{a}_{0}+15 \mathrm{a}_{1}+55 \mathrm{a}_{2} \\
162.5=15 \mathrm{a}_{0}+55 \mathrm{a}_{1}+225 \mathrm{a}_{2} \\
626.7=55 \mathrm{a}_{0}+225 \mathrm{a}_{1}+979 \mathrm{a}_{2}
\end{gathered}
$$

Solving these three equations simultaneous will give us a value of

$\mathrm{a}_{0}=7.1 ; \mathrm{a}_{1}=0.5214 ; \mathrm{a}_{2}=0.1214$

$y=7.1+0.5214 * x+0.1214 * x^{2}$

By using the derived equations (13), (14) and (18) the respective forecasted peak load is shown in table 1 .

The rank of correlation coefficient $\left(r_{x y}\right)$ and Mean absolute percentage error (MAPE) values will be calculated based on equation 11 and 12. The mean and standard deviation of $y$ is calculated by using the respective forecasted peak load values.

$$
\begin{gathered}
r_{x y}=\frac{\sum x_{i} y_{i}-n \bar{x} \bar{y}}{n s_{x} s_{y}} \\
M A P E=M=\frac{1}{n} \sum_{t=1}^{n}\left|\frac{A_{t}-F_{t}}{A_{t}}\right|
\end{gathered}
$$




\section{International Journal of Science and Research (IJSR) \\ ISSN (Online): 2319-7064}

Index Copernicus Value (2013): 6.14 | Impact Factor (2014): 5.611

Table 2: Mean absolute percentage error and rank correlation coefficient values

\begin{tabular}{|c|c|c|c|}
\hline & $\begin{array}{c}\text { Using Linear } \\
\text { trend } \\
\text { Forecasting }\end{array}$ & $\begin{array}{c}\text { Using Compound } \\
\text { growth Forecasting }\end{array}$ & $\begin{array}{c}\text { Using quadratic } \\
\text { regression } \\
\text { Forecasting }\end{array}$ \\
\hline MAPE & 0.025 & 0.018 & 0.019 \\
\hline$r_{x y}$ & 0.8 & 0.798 & 0.795 \\
\hline
\end{tabular}

High value of $r_{x y}$ and low value of MAPE is best for load forecasting. So from table 2 compound growth forecasting is best suited. Based on this the next five years load demand of Jimma town can be forecasted as follows.

From equation (14) $\mathrm{y}=\operatorname{antilog}(0.83+0.0545 * \mathrm{x})$

For the year 2014/15 $(x=6)$ to $2018 / 19(x=10)$ the load forecast of these years based on compound regression method is listed in table 3

Table 3: The peak load forecasted using Compound growth model for the year $2014 / 15$ to $2018 / 19$

\begin{tabular}{|c|c|}
\hline Year $(\mathrm{X})$ & Compound growth Forecasted peak load (MW) \\
\hline $2014 / 15(\mathrm{x}=6)$ & 14.35 \\
\hline $2015 / 16(\mathrm{x}=7)$ & 16.27 \\
\hline $2016 / 17(\mathrm{x}=8)$ & 18.45 \\
\hline $2017 / 18(\mathrm{x}=9)$ & 20.92 \\
\hline $2018 / 19(\mathrm{x}=10)$ & 23.71 \\
\hline
\end{tabular}

As it is seen from table 3; after four years ahead the peak load demand of Jimma town will be $23.71 \mathrm{MW}$. Since the maximum capacity of the present distribution system substation is $16 \mathrm{MW}$; extra $7.71 \mathrm{MW}$ is looked-for to customers after four years. So to avoid shortage of power due to the capacity of the present distribution system; in the coming year's expansion of the present distribution power system must be done in addition to functionalizing of the newly installed distribution substation.

\section{Conclusion}

Long-term peak load forecasts drives various plans and decisions on investments in modern power systems. In this research, the ultimate focus of forecasting Jimma town peak load by using different trending methods is achieved. The load forecasting of the next five years is done based on the historical data collected from south western region transmission maintenance and substation. The linear regression, compound-growth and quadratic regression were tested and based on the values of mean absolute percentage error and rank correlation coefficient the most suitable is chosen

The maximum capacity of Jimma town distribution substation is $16 \mathrm{MW}$ and from the forecasted load in 2015 the peak load demand will be $16.27 \mathrm{MW}$ which is beyond the capacity of distribution substation can supply. In order to supply the peak load demand the new distribution substation must be functional in this year.

\section{References}

[1] Marko C. Assessment of power system reliability methods and application. London. Springer-Verlag; 2011.

[2] Al Mamun M., and Negasaka K., "Artificial neural networks applied to long-term electricity demand forecasting", Proceedings of the Fourth International Conference on Hybrid Intelligent Systems (HIS'04), pp. 204-209, Dec. 2004.

[3] Dang Khoa T. Q. and Oanh P. T., "Application of Elman and neural wavelet network to long-term load forecasting", ISEE Journal, track 3, sec. B, No. 20, pp. $1-6,2005$.

[4] Al-Hamidi H. M. and Soliman S. A., "Long term/ midterm electric load forecasting based on short-term correlation and annual growth", Electric Power System Research (Elsevier), Vol. 74, No. 3, pp. 353-361, June 2005.

[5] Willis, H.L., "Load Forecasting for Distribution Planning-Error and Impact on Design," IEEE Transactions on Power Apparatus and Systems, vol.PAS-102, no.3, pp.675-686, March 1983

[6] Dang Khoa T. Q. and Oanh P. T., "Application of Elman and neural wavelet network to long-term load forecasting", ISEE Journal, track 3, sec. B, No. 20, pp. $1-6,2005$.

[7] Al-Hamidi H. M. and Soliman S. A., "Longterm/ midterm electric load forecasting based on short-term correlation and annual growth", Electric Power System Research (Elsevier), Vol. 74, No. 3, pp. 353-361, June 2005.

[8] Engineering and design hydropower proponent, "Load forecasting methods," in EM 110-2-1701, appendix B, Dec 1985.

[9] Genethliou D. and Feinberg E. A., Load forecasting, Applied mathematics for restructured electric power system: optimization, control and computational intelligence (J. H. Chow, F.F. Wu, and J. J. Momoh, eds.), chapter 12, pp. 269-285, 2005.

[10] Yen-Ting Chao; Sheng-Ta Lee; Hong-Chan Chang; Tsai-Hsiang Chen, "An improvement project for distribution transformer load management in Taiwan," IEEE Transactions on Power Systems, vol.18, no.2, pp. 875-881, May 2003

[11] Gross, G.; Galiana, F.D., "Short-term load forecasting," Proceedings of the IEEE, vol.75, no.12, pp. 1558-1573, Dec. 1987

[12] Chow, M.-Y.; Tram, H., "Application of fuzzy logic technology for spatial load forecasting," IEEE Transactions on Power Systems, vol.12, no.3, pp.1360 1366, Aug 1997

[13] Kandil, M.S.; El-Debeiky, S.M.; Hasanien, N.E., "Long-term load forecasting for fast developing utility using a knowledge-based expert system," IEEE Transactions on Power Systems, vol.17, no.2, pp.491496, May 2002

[14] Powers, M.W., "The analytical Monte Carlo method for approximating the distribution of a plant's electrical generation," IEEE Transaction on Energy Conversion, vol.3, no.3, pp.433-439, Sep 1988

[15] Fung Y. H., Tummala V.M., Forecasting of electricity consumption: a comparative analysis of regression and 


\section{International Journal of Science and Research (IJSR) \\ ISSN (Online): 2319-7064}

Index Copernicus Value (2013): 6.14 | Impact Factor (2014): 5.611

artificial neural network models.IEE Second International Conference on Advances in Power System Control, Operation and Management, Hong Kong pgs.782-7, 1993.

[16] Ghods L., Kalantar M., Methods for Long-Term Electric Load Demand Forecasting; a Comprehensive Investigation. IEEE. 2008

[17] Boweman. B, R.T.O'connell, Applied Statistics, McGraw-Hill, 1997.

[18] Sophia Peter, Long-term load forecasting options in Georgia, 2013

[19] Demand Forecasting for Electricity, www.teriin.org/pub/papers/ft30.pdf.

\section{Author Profile}

Mr. Emiyamrew M. is born in Gondar, Ethiopia $\mathrm{He}$ is having $5+$ years of teaching experience. He is a lecturer in Department of Bio-medical Engineering, Jimma institute of technology, Jimma University, Ethiopia. He is also institutional reform officer of the institute. His educational background is Electrical power Engineering. His research interest includes power system operation and control, power reliability analysis of electrical power generation, transmission and distribution systems, power quality and harmonics analysis of industries

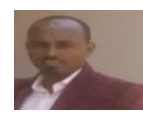

Mr. Melaku M. is born in Axum, Ethiopia. He is having $5+$ years of teaching experience. He is lecturer in School of Electrical and Computer Engineering, Jimma institute of technology, Jimma University, Ethiopia. His educational background is Electrical power Engineering. His research interests includes power system operation and control, electrical power transmission and distribution, power quality, reliability, power economics and power electronics. 